\title{
A comparative study of biological production in eastern boundary upwelling systems using an artificial neural network
}

\section{Z. Lachkar and N. Gruber}

Environmental Physics, Institute of Biogeochemistry and Pollutant Dynamics, ETH Zurich, Universitätstrasse 16, 8092 Zurich, Switzerland

Correspondence to: Z. Lachkar (zouhair.lachkar@env.ethz.ch)

Received: 22 September 2011 - Published in Biogeosciences Discuss.: 4 October 2011

Revised: 26 December 2011 - Accepted: 5 January 2012 - Published: 16 January 2012

\begin{abstract}
Eastern Boundary Upwelling Systems (EBUS) are highly productive ocean regions. Yet, substantial differences in net primary production (NPP) exist within and between these systems for reasons that are still not fully understood. Here, we explore the leading physical processes and environmental factors controlling NPP in EBUS through a comparative study of the California, Canary, Benguela, and Humboldt Current systems. The NPP drivers are identified with the aid of an artificial neural network analysis based on self-organizing-maps (SOM). Our results suggest that in addition to the expected NPP enhancing effect of stronger equatorward alongshore wind, three factors have an inhibiting effect: (1) strong eddy activity, (2) narrow continental shelf, and (3) deep mixed layer. The co-variability of these 4 drivers defines in the context of the SOM a continuum of 100 patterns of NPP regimes in EBUS. These are grouped into 4 distinct classes using a Hierarchical Agglomerative Clustering (HAC) method. Our objective classification of EBUS reveals important variations of NPP regimes within each of the four EBUS, particularly in the Canary and Benguela Current systems. Our results show that the Atlantic EBUS are generally more productive and more sensitive to upwelling favorable winds because of weaker factors inhibiting NPP. Perturbations of alongshore winds associated with climate change may therefore lead to contrasting biological responses in the Atlantic and the Pacific EBUS.
\end{abstract}

\section{Introduction}

Eastern boundary upwelling systems (EBUS), i.e. the California, Humboldt, Canary, and Benguela upwelling systems, are among the most productive marine ecosystems in the world and have long been recognized for supporting some of the world's major fisheries (Pauly and Christensen, 1995; Bakun, 1990, 1996; Carr, 2001; Carr and Kearns, 2003; FAO, 2009). The high productivity supports a large export of organic carbon, not only vertically (Muller-Karger et al., 2005) but also laterally into the open ocean, enhancing heterotrophic processes there (e.g. Arístegui et al., 2004). Despite the upwelling of carbon rich-waters to the surface, the high organic carbon export tends to make these systems either neutral or small sources of $\mathrm{CO}_{2}$ to the atmosphere (see e.g. Chavez and Takahashi, 2007). Thus, identifying what controls biological production within EBUS is not only critical to the understanding of functioning of these ecosystems, but is also essential for more accurate assessments of the marine carbon cycle at regional and global scales.

The basic mechanism responsible for the high productivity in EBUS is well understood: equatorward winds along the eastern boundaries of the Atlantic and Pacific force an offshore Ekman transport, which drives upwelling of deep nutrient-rich water into the euphotic zone, where favorable light conditions sustain phytoplankton growth (Allen, 1973; Brink, 1983a). Nevertheless, individual EBUS show substantial differences in chlorophyll standing stock and net primary production (NPP) for reasons that remain not fully understood (Carr, 2001). The comparison of different EBUS provides a framework for generalizing individual observations 
and developing a unified conceptual model of coastal upwelling production regimes. Furthermore, by examining the contrasts between the different EBUS one can gain insight into how different environmental conditions can alter the sensitivity of biological production to climate change associated wind perturbations (Bakun, 1990; Shannon et al., 1992; Schwing and Mendelssohn, 1997; Mendelssohn, 2002; McGregor et al., 2007).

While numerous studies have focused on specific EBUS in order to elucidate their particular dynamics (Hickey, 1998; Barton et al., 1998; Mittelstaedt, 1983; Fennel, 1999; Brink, 1983b), less effort has been devoted to identify common patterns and contrasting features between various EBUS (Mackas et al., 2006). This is at least partially due to the lack of homogeneous and sufficiently dense observational coverage over the different EBUS. Yet, recent measurements of ocean color by satellite remote sensing has made it possible to map the near-surface chlorophyll distribution and spurred the development of empirical models that estimate NPP from such satellite data (Longhurst et al., 1995; Carr, 2001; Behrenfeld and Falkowski, 1997; Marra et al., 2003; Kahru et al., 2009). During the last decade, several satellite data based studies investigated statistical correlations relating biological production in EBUS to various physical and environmental properties. The most extensive work in this regard was done by Carr (2001) and Carr and Kearns (2003) who examined some potential NPP drivers that they separated into local forcing processes such as upwelling favorable winds and large-scale circulation related factors like the depth of the thermocline. Yet, the statistical analyses in these studies have been performed over each upwelling system separately, which makes it difficult to generalize the results and to easily interpret the differences between EBUS. More recently, Patti et al. (2008) investigated the relationship between surface chlorophyll and several physical and environmental factors at various sites along the 4 major EBUS. They found that near-surface concentrations of nitrate together with the width of the continental shelf explain up to $70 \%$ of the total variance of surface chlorophyll across the different sites. Rossi et al. $(2008,2009)$ explored the relationship between biological activity and the intensity of horizontal mixing in the major EBUS and found a strong negative correlation between the magnitude of lateral stirring and surface chlorophyll standing stocks across the 4 upwelling systems. Finally, Gruber et al. (2011) analyzed satellite based estimates of biological production in the major EBUS with a focus on the role of mesoscale activity. They found that upwelling strength together with the mesoscale eddy activity explain up to $65 \%$ of the total variance of NPP in the 4 systems. Additionally, their results indicate that eddies reduce NPP in EBUS substantially.

While these studies provided many insights into the potential factors controlling NPP in EBUS, many aspects such as the relative importance of the different drivers as well the nature of their relationship to NPP are still not fully under- stood. This is, at least partially, due to the linear data analysis techniques used in those studies, which may not be suited to extract interpretable patterns from non linear data sets. In particular, these techniques fail to identify relevant drivers when many of them are highly correlated (Harrell, 2001; Cohen et al., 2002; Belsley et al., 1980; Gotelli and Ellison, 2004). Moreover, linear statistics are inappropriate to explain complex dependencies with threshold effects such as inhibition and limitation behaviors in biological and ecological systems. Therefore, given the complexity and the possibly non-linear dynamics driving EBUS, more sophisticated tools are needed to properly explore their functioning and uncover their variability.

Here we use self-organizing maps (SOM), a class of unsupervised artificial neural networks adept at pattern recognition and classification also known as Kohonen maps (Kohonen, 1989, 2000). SOM provide a powerful analysis and visualization approach for studying structure in complex data sets and have a number of advantages over traditional statistical methods like principal component analysis (PCA) (Astel et al., 2007) and empirical orthogonal functions (EOF) (Liu et al., 2006). First and foremost, they accommodate nonlinear correlations in the data (Dayhoff, 1990). In addition, SOM are more robust in handling noisy and missing data, and they do not require prior assumptions about the data, such as equality of variances or distribution normality (Chen and Ware, 1999).

Finally, we use the characterization of EBUS to provide an objective framework for categorizing these ecosystems based solely on the mechanisms controlling biological production. Although previous review studies by Hill et al. (1998), Brink (2005) and Mackas et al. (2006) investigated in detail common features and processes at work in EBUS, to our knowledge no objective classification of these ecosystems based on their production regimes has been proposed. The main focus of this paper is then two-fold: (i) to identify the most relevant drivers of NPP in EBUS and how they affect the biological activity, and (ii) to provide an objective classification of EBUS based on their respective production regimes.

\section{Methods}

\subsection{Data description}

In addition to the alongshore wind stress, the Ekman suction induced by the curl of the wind stress (McCreary et al., 1987), the topography of the continental shelf (Batteen et al., 2007; Patti et al., 2008; Marchesiello and Estrade, 2009; Lachkar and Gruber, 2011a), the local density stratification in the upper ocean (Marchesiello and Estrade, 2009) and the mesoscale eddy activity (Rossi et al., 2008; Marchesiello and Estrade, 2009; Gruber et al., 2011) have been considered as potential drivers for coastal NPP. Additional variables were considered in this study such as nitrate concentrations 
Table 1. List of variables and sources of the datasets.

\begin{tabular}{lll}
\hline Variable Name & Abreviation & Data set \\
\hline Net Primary Production & NPP & SeaWiFS - AVHRR \\
Upwelling Index & UWI & QuikSCAT \\
Ekman suction velocity & Ekm $w$ & QuikSCAT \\
Photosynthetically Available Radiation & PAR & SeaWiFS \\
Sea Surface Temperature & SST & AVHRR \\
Eddy Kinetic Energy & EKE & AVISO \\
Nitrate concentration at $50 \mathrm{~m}$ & Ntr50 & WOA2001 \\
Mixed Layer Depth & MLD & deBoyer Montegut 2004 \\
Shelf Width & SHW & ETOPO2 \\
\hline
\end{tabular}

at $50 \mathrm{~m}$, Sea Surface Temperature (SST), and Photosynthetically Available Radiation (PAR). Table 1 shows the list of variables used here.

We used satellite derived observations of: (1) monthly wind stress from QuikSCAT data set on a $25 \mathrm{~km}$ grid, (2) monthly chlorophyll-a concentrations from SeaWiFS data on a $9 \mathrm{~km}$ grid, (3) monthly PAR also from SeaWiFS, (4) monthly SST from AVHRR on a $9 \mathrm{~km}$ grid, and (5) monthly eddy-kinetic energy (EKE) from AVISO on a Mercator $1 / 3^{\circ}$ grid estimated from the geostrophic velocity anomalies calculated from merged Topex/Poseidon/ERS/Jason1/ENVISAT maps. Satellite observations cover 41 months from August 1999 to December 2002. Given that the main focus of this study is to identify NPP drivers, this represents a sufficient amount of data to derive statistically significant results although covering a relatively short period. Net primary production was computed from chlorophyll-a, SST, and PAR using the Vertically Generalized Production Model (VGPM) (Behrenfeld and Falkowski, 1997). NPP inferred from such models are associated with a substantial amount of uncertainties and biases, particularly in coastal waters (see e.g. Kahru et al., 2009). However, such potential biases in NPP are relatively inconsequential for our analyses, as long as they tend to be proportional to NPP. This is because our analysis focuses on relationships rather than the absolute magnitude of NPP. This is supported by our finding that when we use the NPP model proposed by Carr (2001) in a separate experiment, our results did not change significantly.

An upwelling index (UWI), defined as the offshore component of Ekman transport along the coasts (a mass flux per meter of coastline) was calculated using the QuikSCAT wind stress and taking into account the local orientation of the coast. We also calculated the Ekman suction velocity using the curl of the wind stress. Monthly data of nitrate concentration at $50 \mathrm{~m}$ was derived from the World Ocean Atlas 2001 climatology (Conkright et al., 2002), and we used a monthly climatology of mixed layer depth (MLD) from de Boyer Montégut et al. (2004). The use of climatological monthly data for nitrate concentration and mixed layer depth is due to the lack of observations of these two pa- rameters covering the period of the study for the 4 EBUS. Finally, the shelf width was estimated as the offshore extent of $200 \mathrm{~m}$ isobath using the bathymetry file ETOPO2 from NGDC (National Geophysical Data Center) (Smith and Sandwell, 1997).

Data were analyzed for each of the four eastern boundary upwelling systems, extending from the coastline to $500 \mathrm{~km}$ offshore in the zonal direction and from $24^{\circ} \mathrm{N}$ to $48^{\circ} \mathrm{N}$ for the California Current System, from $12^{\circ} \mathrm{N}$ to $34^{\circ} \mathrm{N}$ for the Canary Current System, from $10^{\circ} \mathrm{S}$ to $34^{\circ} \mathrm{S}$ for the Humboldt Current System, and from $10^{\circ} \mathrm{S}$ to $30^{\circ} \mathrm{S}$ for the Benguela Current System. These boundaries were chosen to include as much of these upwelling systems as possible, but to exclude other features that are unrelated to coastal upwelling, such as the Agulhas rings in the Benguela Current System. The offshore extension of EBUS in our analysis is identical to the one previously used by Carr (2001). Changing slightly this definition by limiting our analysis to the first $400 \mathrm{~km}$ offshore did not have any significant impact on the results. For EKE the values in the nearshore $50 \mathrm{~km}$ were not included, as their errors are substantially larger. These errors are essentially associated with the tidal signal correction (Matsumoto et al., 2000; Volkov et al., 2007), but can also result from the land contamination in the atmospheric corrections (Volkov et al., 2007). Data were then averaged over $1^{\circ}$ bins in meridional direction and over the $500 \mathrm{~km}$ coastal strip (see Fig. 1). The shelf width data (90 meridional bins) were repeated over time in order to produce a vector with the same dimensionality as the time-series variables. The monthly climatological data (mixed layer depth and nitrate concentration) were also repeated in time to cover the full period. Therefore, the input data base that we explore here contains 41 (months) $\times 90$ (meridional bins) $=3690$ observations of 9 different variables (NPP +8 potential drivers).

\subsection{Self-organizing maps}

During the last decade, the method of Self-organizing maps (SOM) has been used successfully in various areas of geosciences such as climate variability (Cavazos, 2000; Reusch et al., 2007; Leloup et al., 2007), physical oceanography 
Table 2. Pearson correlation coefficient $(r)$ between the potential drivers and NPP.

\begin{tabular}{lrrrrrrrrr}
\hline & UWI & EKE & MLD & SHW & PAR & SST & Ekm $_{w}$ & Ntr50 & NPP \\
\hline UWI & 1 & -0.12 & -0.29 & 0.1 & 0.52 & 0.33 & 0.04 & 0.44 & 0.55 \\
EKE & - & 1 & -0.1 & -0.04 & -0.14 & 0.01 & -0.09 & -0.16 & -0.22 \\
MLD & - & - & 1 & 0.02 & -0.58 & -0.48 & -0.22 & -0.34 & -0.27 \\
SHW & - & - & - & 1 & 0.05 & 0.19 & -0.14 & -0.08 & 0.19 \\
PAR & - & - & - & - & 1 & 0.4 & 0.11 & 0.27 & 0.45 \\
SST & - & - & - & - & - & 1 & 0.29 & 0.40 & 0.08 \\
Ekm $_{w}$ & - & - & - & - & - & - & 1 & 0.55 & 0.17 \\
Ntr50 & - & - & - & - & - & - & - & 1 & 0.47 \\
NPP & - & - & - & - & - & - & - & - & 1 \\
\hline
\end{tabular}
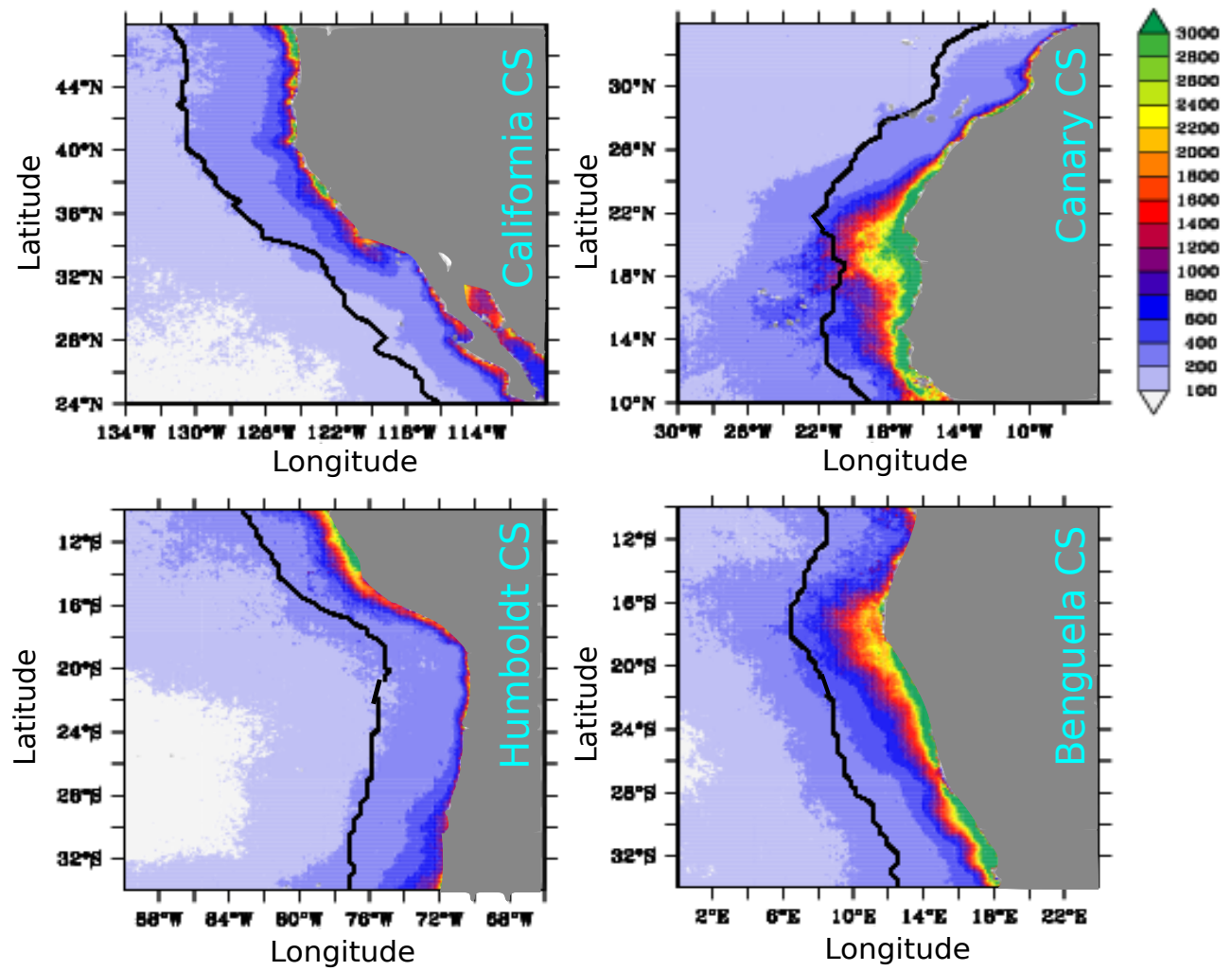

Fig. 1. Annual mean net primary production (NPP) in $\mathrm{g} \mathrm{C} \mathrm{m}^{-2} \mathrm{yr}^{-1}$ for the California, Canary, Humboldt and Benguela systems. The NPP is computed from chlorophyll-a, SST, and PAR using the Vertically Generalized Production Model (VGPM) (Behrenfeld and Falkowski, 1997). The black lines indicate for each EBUS the limits of the $500 \mathrm{~km}$ offshore coastal band used in this study.

(Richardson et al., 2002; Liu and Weisberg, 2005) and environmental applications (Park et al., 2001, 2003; Saraceno et al., 2006; Solidoro et al., 2007). The SOM implements a nonlinear, topology-preserving mapping from a higher dimensional feature space to a lower (usually 2) dimensional grid of computational units called neurons. This means that similar objects (in our case EBUS observations) are mapped close together on the grid (Fig. 2). The topology conservation property of SOM is ensured by a neighborhood relation connecting adjacent neurons on the map. Each map unit or neu- ron is associated with a reference or prototype vector, made of as many components as the number of variables in the dataset, so that it can be seen as a local summary or generalization of similar observations. For instance, each neuron in this study corresponds to a specific pattern of EBUS production regimes, consisting of a particular level of NPP and the associated potential drivers.

SOM learn by an iterative process, whereby input data are presented successively to the map. Observations are associated with their best representative neurons, called best 
High dimensional

observation space

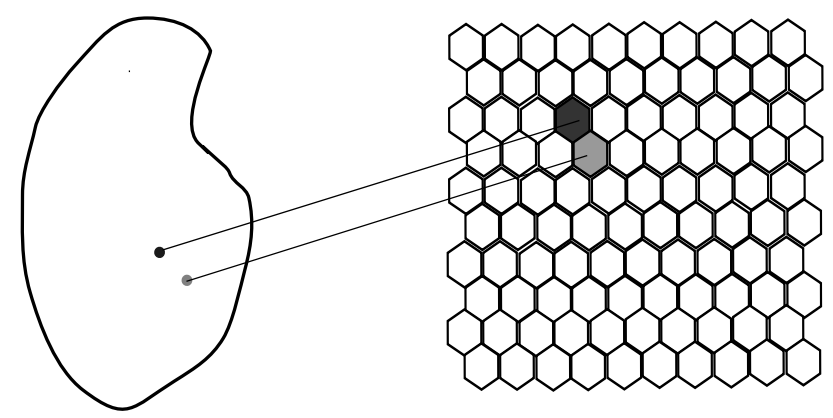

Fig. 2. A sketch showing the geometry of the SOM twodimensional lattice with 100 neurons and the correspondence between SOM and the input space. Thanks to SOM's topography preservation property, neurons associated with similar observations in the input space are close to each other on the map.

matching units (BMUs). Following an unsupervised learning procedure, the training algorithm adjusts the prototype vectors associated with neurons of the map at each iteration step in such a way to better match the input data distribution (Kohonen, 1989, 2000). At the end of the training phase, the SOM approximates the probability density function of the input data. For more details of the SOM training algorithm, see Kohonen (2000) for theoretical considerations and Richardson et al. (2003) for examples of applications of SOM in oceanography.

In practice, when using a SOM one has to decide a priori the size of the map, i.e., the number of the neurons of the map, and a few parameters of the training algorithm. No theoretical principle for the choice of the map size exists (Richardson et al., 2003). Rather, the number of neurons depends on the complexity of the problem and on the total number of observations. Here, we use a $10 \times 10$ rectangular map with 100 neurons. Using slightly different sizes does not affect the results noticeably. A hexagonal cell structure was chosen because it favors neither the horizontal nor the vertical direction (Kohonen, 2000) (Fig. 2). The weights of the neurons were initialized using the linear method described in Kohonen (2000). Finally, we opted for a Gaussian neighborhood function as it has a lower topographic error ensuring a better mapping.

\subsection{Selection of drivers}

In order to capture the key processes controlling NPP in EBUS, we should provide SOM with the most relevant drivers explaining the NPP variability. We started first by assessing the relationship of each predictor variable with NPP in a bivariate sense. Pearson correlation coefficients were calculated for the eight variables and are presented in Table 2. The upwelling index has the strongest linear relationship to
NPP $(r=0.55)$, while SST has the weakest $(r=0.08)$. Despite the low magnitude of the latter relationship, it is still statistically significant. Yet, a simple ranking of correlation coefficients can not be used to determine the relative importance of individual drivers as these coefficients are inappropriate to describe correlations for multivariate data. Therefore, we used a stepwise multilinear regression to better assess the statistical significance of the relationship between NPP and the potential drivers. This analysis showed that all the 8 potential drivers have a statistically significant correlation with NPP. Yet, ranking the relative importance of variables using a stepwise linear regression can be misleading because of the relatively high correlations between many drivers potentially conveying the same information. A review of the correlations in Table 2 reveals, indeed, a strong interdependence between the predictors.

To circumvent the problem of redundancy in the data, we used a feature selection method (Liu and Motoda, 1998) to reduce the number of potential drivers and retain only the most important predictors or features that contribute to the information content of the data. Feature selection consists in compressing the data through elimination of redundant or irrelevant features. Following Laine and Similä (2004) and Laha (2005) we used a SOM-based algorithm to perform this task (see supplementary information for details). Two subsets of drivers emerge: these include the upwelling index and nitrate concentration at $50 \mathrm{~m}$ depth, in addition to three common drivers: the eddy kinetic energy, the mixed layer depth and the continental shelf width. As shown previously in Table 2, nitrate availability at $50 \mathrm{~m}$ is strongly correlated with the upwelling strength. The source of this tight correlation is that the high concentrations of nitrate in EBUS are actually largely a consequence of the upwellingfavorable winds. Therefore, we decided to use the latter, i.e., upwelling strength, as an NPP driver. It is worth noting that neither SST nor PAR appears in the best set of drivers, although both are involved in the NPP computation following the VGPM. This is because both are strongly correlated with the upwelling index and the mixed layer depth (Table 2), and hence add little independent information to describe NPP variability. Next, we explore the map trained with this set of drivers, i.e., upwelling strength, shelf-width, eddy-kinetic energy, and mixed layer depth and we investigate their relationship to the NPP.

\section{Results}

\subsection{SOM-derived NPP patterns}

The SOM analysis produces a continuum of coastal upwelling production patterns representing the range of production regimes in the input data and displays them in a twodimensional output map (Fig. 3). The continuum of patterns ranges from those with very low NPP at the top right corner 


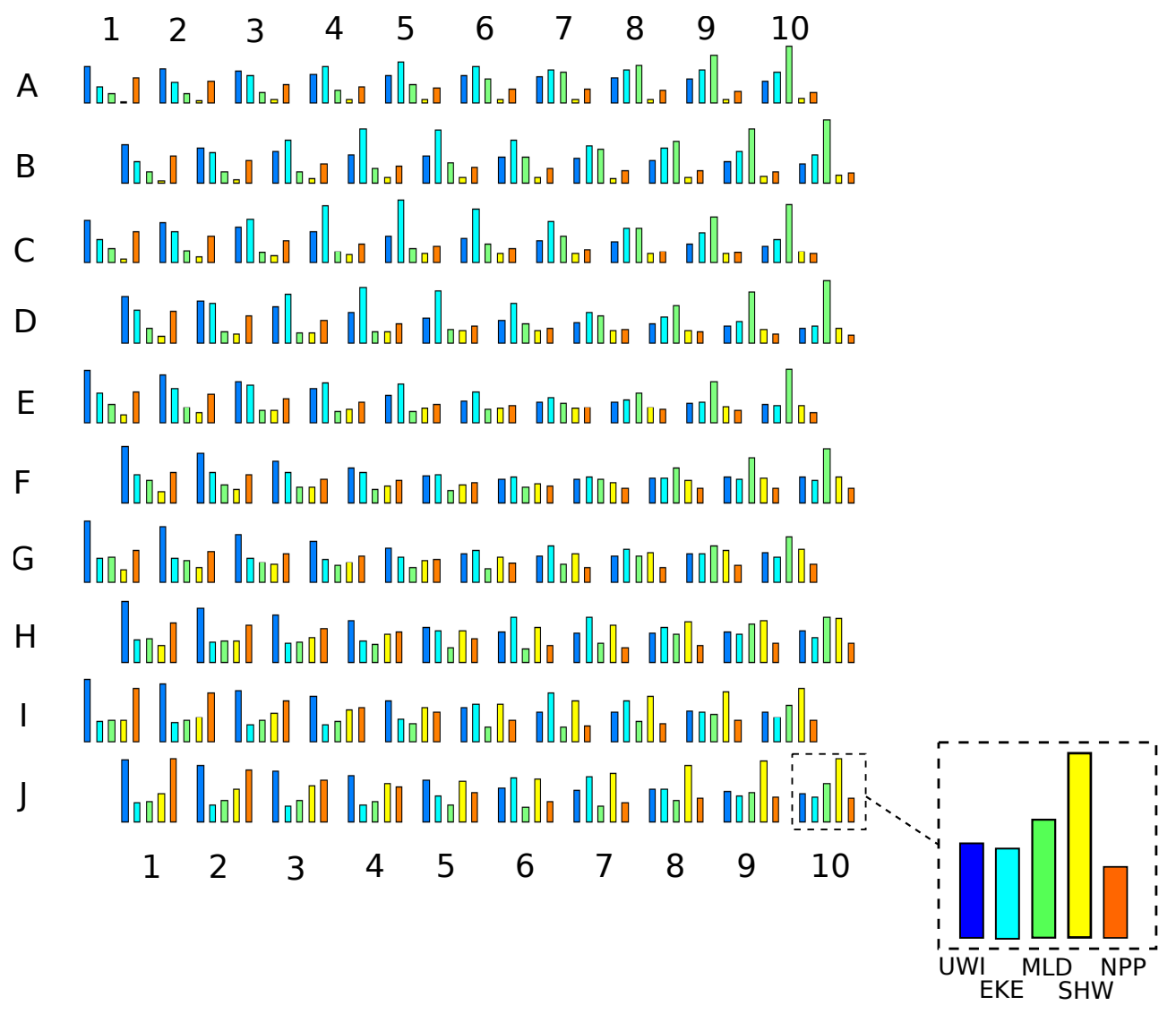

Fig. 3. Visualization of EBUS production patterns on the SOM. Each neuron corresponds to a prototype of production regime defined by a given combination of NPP and the 4 drivers. For comparison between different variables, data is normalized between 0 and 1 .

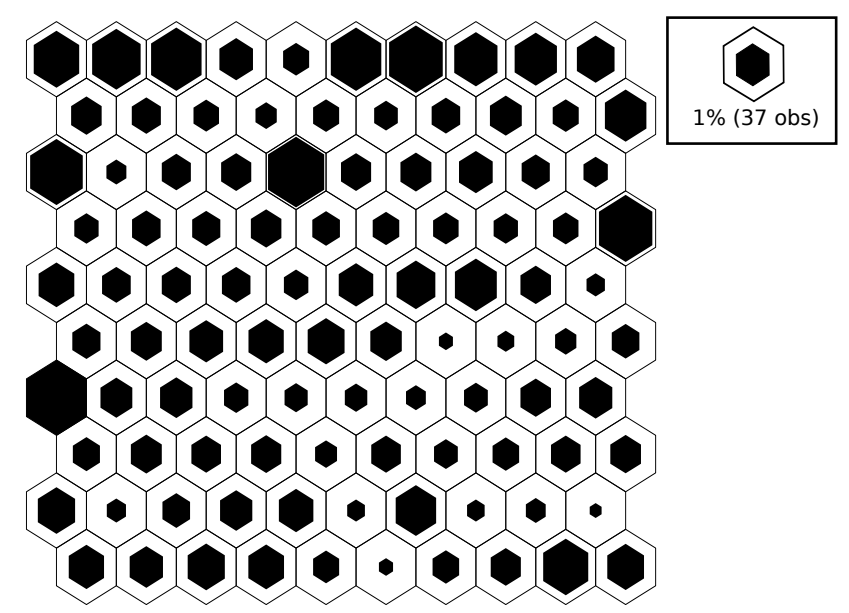

Fig. 4. Frequency of occurrence of the SOM patterns. The area of the black hexagons inside each neuron is proportional to the frequency of the pattern it represents. of the map to very high NPP in the bottom left corner. This gradual change in production regimes is associated with continuous changes in the NPP drivers across the map, with the upwelling index, the mixed layer depth and the shelf width reaching their maximum values in the bottom left, top right and bottom right corners, respectively. The eddy kinetic energy, on the other hand, shows an absolute and a secondary maximum in the interior of the map. The frequency of occurrence of the different patterns (classes) ranges from $0.14 \%$ for the least common neuron to about $3.5 \%$ for the most common (Fig. 4) The top area of the map corresponds to the most densely populated region in the observation space with the first row representing about $20 \%$ of the total observations. Overall, observations are continuously distributed across the map with no empty neurons. However, the presence of neurons with relatively low density suggests the existence of natural boundaries among the data separating distinct clusters.

\subsection{On the relationship between drivers and NPP}

A better qualitative understanding of the different correlations in the data can be derived from a visual inspection of 

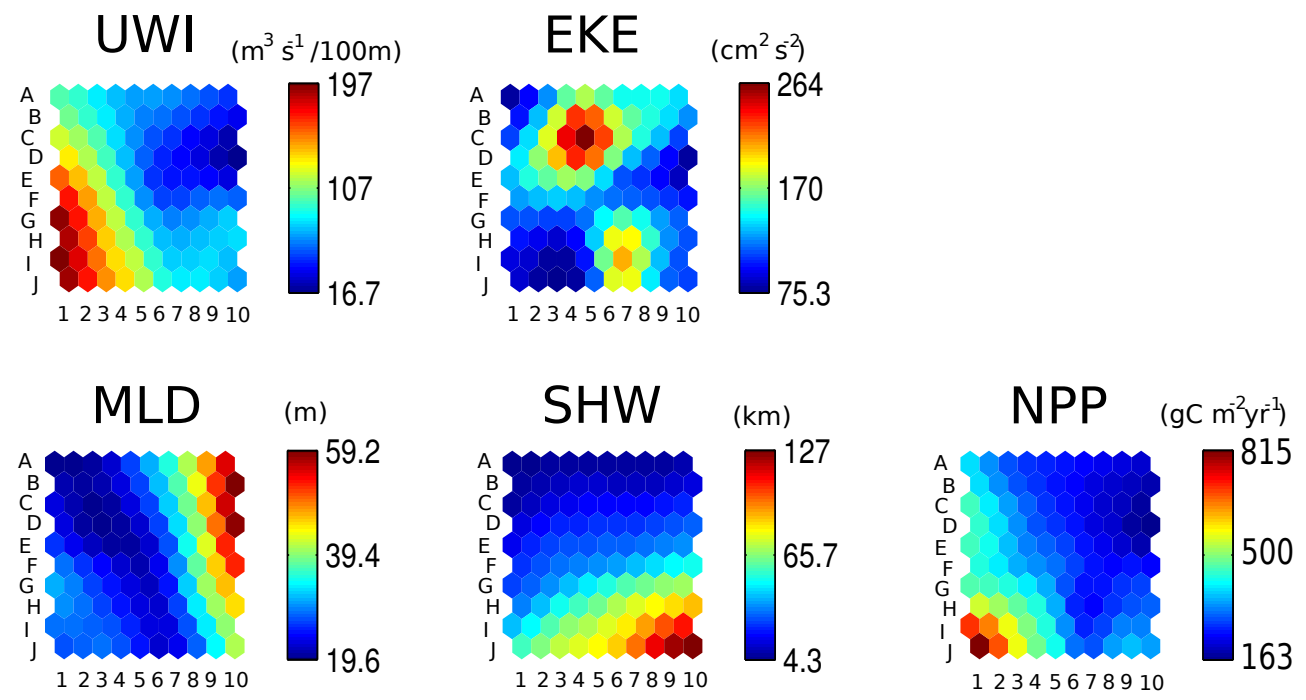

Fig. 5. Component planes of the SOM. Each plane shows the distribution of one variable across the map.

the component planes depicting the variability of each parameter on the map (Fig. 5). Consistent with previous analyses and the canonical view, NPP and the upwelling index show a strong coherence. The bottom left corner characterized by very productive upwelling conditions is also the map area where the upwelling index is the largest. Correspondingly, relatively unproductive conditions in the top right corner of the map are associated with weak wind forcing. This confirms that, to first order, NPP variations in the EBUS are driven by differences in alongshore wind strength (Carr, 2001; Carr and Kearns, 2003). Yet, when further examining the map, exceptions to this rule arise. For instance, in the bottom left quarter of the map, several neurons have similar NPP although those along the left side (neurons F1 to I1) have a substantially higher upwelling index than the ones near the bottom (neurons J2 to J5) of the map. This suggests that NPP is enhanced below the second diagonal of the map and limited above this line due to one of the three remaining drivers. With low values above the second diagonal line and high values below, only the shelf width can explain this contrasting NPP response to wind forcing. Therefore, these results suggest that narrow continental shelves are associated with reduced coastal NPP. For neurons G6-G8 to J6-J8 in the bottom right quarter, NPP shows a local minimum, whereas neither the upwelling index nor the shelf width have local extrema in this area of the map. In contrast, the eddy kinetic energy has a local maximum matching the area of relatively low NPP near the bottom right corner. This implies that the eddy kinetic energy is a discriminating driver in this area and that intense eddy activity is associated with lower production. Finally, deep mixed layers also appear to play an inhibiting role, as the regions with the deepest mixed layers tend to be the least productive.
For a better understanding of the relationship between the NPP and its drivers, we plotted for each of the four drivers their relationship to the NPP across the map (Fig. 6). While there is a clear linear correlation between the upwelling index and NPP, the relationship between the three remaining drivers and NPP is of a different nature. That is, the effect of these drivers on the NPP starts to be important only when they reach extreme values. For instance, the shelf width appears to restrict NPP only when it is very narrow, whereas a wide shelf does not lead systematically to high production. Similarly, when the eddy kinetic energy or the mixed layer depth are low or moderate, neither of them seem to have any clear impact on the production. But when they are high, NPP tends to be low. The relationship between these three drivers and NPP is therefore asymmetric and can be viewed as a limitation relationship. Because of this asymmetry, we shall term these drivers inhibiting factors in contrast to the upwelling index which is the primary driver for NPP in EBUS.

In summary, SOM analysis identified a continuum of classes of physical conditions enhancing or inhibiting biological production. Next, we use these findings to provide an objective classification of production regimes in EBUS and we investigate the similarities and differences between the four major EBUS.

\subsection{A production regime based classification of EBUS}

The co-variability of the alongshore wind together with the three inhibiting factors provides an objective framework to define a typology of coastal upwelling ecosystems on the basis of their production regimes. While SOM provided already a first classification of these regimes into 100 patterns, a further clustering is needed for a more synthesized representation of the biological production in EBUS. To this end, 

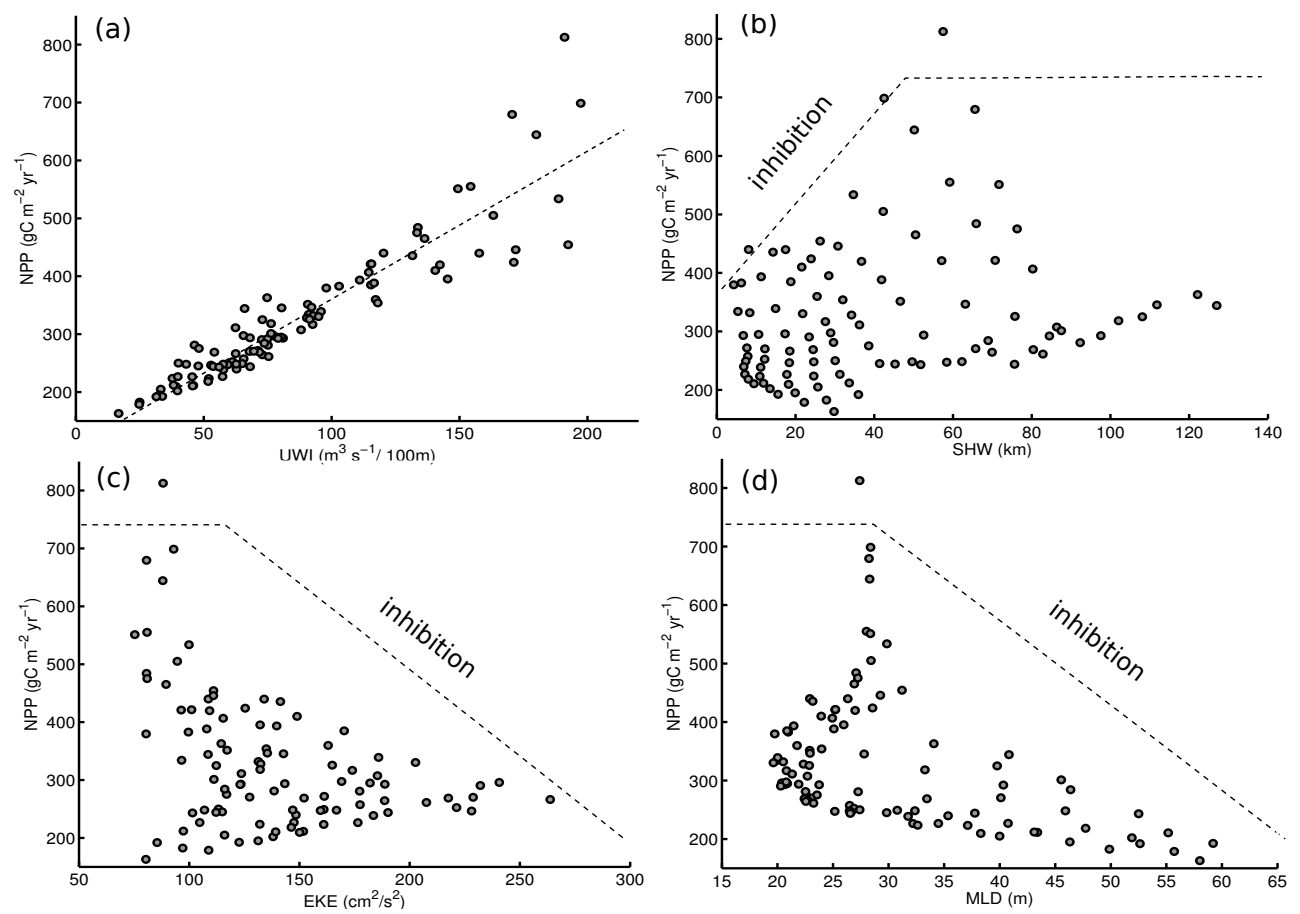

Fig. 6. The relationship of NPP to the drivers: (a) upwelling index, (b) shelf width, (c) eddy kinetic energy, and (d) mixed layer depth among SOM neurons.

we use the Hierarchical Agglomerative Clustering (HAC) method (Jain and Dubes, 1988). HAC treats each neuron as a singleton cluster (i.e., a class of one object) and then successively combines pairs of clusters based on their similarity until all clusters have been merged into a single cluster that contains all neurons.

An HAC clustering can be graphically represented by a tree structure (dendrogram) as shown in Fig. 7. Each merger of two clusters is represented by a node. The length of each branch connecting two consecutive nodes reflects the similarity between the clusters that were merged. This allows for the cutting of the dendrogram where the gap between two successive combinations is largest as such large gaps arguably separate "natural" clusterings, i.e. classes. Applying this criterion retains four classes, with the key separating characteristics being shelf width and upwelling strength, respectively. Consequently, the four classes retained here correspond to the four combinations of high and low values of these two parameters (Fig. 7). Class 1 groups together observations with a relatively wide shelf and strong upwelling index, i.e., strong alongshore wind. These conditions correspond to neurons in the bottom left corner of the map (Fig. 8). These neurons are also characterized by low eddy kinetic energy and shallow mixed layers. Combining favorable upwelling conditions with generally weak inhibiting factors, this class has the most productive conditions with a NPP of $545 \pm 267 \mathrm{~g} \mathrm{C} \mathrm{m}^{-2} \mathrm{yr}^{-1}$ (mean \pm 1 -standard deviation) (Fig. 9). Class 2 groups together observations with a wide shelf, but relatively weak upwelling. These correspond to neurons in the bottom right corner of the map, i.e. neurons characterized by moderate to relatively high eddy kinetic energy and shallow mixed layers (Fig. 8). Having relatively weak forcing and low to moderate inhibiting factors, the biological production in this class is relatively low ( $300 \pm 160 \mathrm{~g} \mathrm{C} \mathrm{m}^{-2} \mathrm{yr}^{-1}$ ) (Fig. 9). Class $3 \mathrm{en}-$ compasses regions with a narrow continental shelf and weak upwelling. These are neurons in the top right corner of the map, which are also characterized by deep mixed layers and moderate levels of eddy kinetic energy (Fig. 8). Due to relatively weak wind forcing and strong limiting factors, the upwelling conditions grouped in class 3 are the least productive with a mean NPP of only $200 \pm 65 \mathrm{~g} \mathrm{C} \mathrm{m}^{-2} \mathrm{yr}^{-1}$ (Fig. 9). Finally, class 4 combines regions with a narrow continental shelf and moderate wind forcing. These are neurons in the top left quarter of the map, which exhibit moderate to high eddy kinetic energy and shallow mixed layers (Fig. 8). Due to relatively strong limiting factors and only moderate wind forcing, the biological production associated with these upwelling conditions is generally low with a mean value of $310 \pm 140 \mathrm{~g} \mathrm{C} \mathrm{m}^{-2} \mathrm{yr}^{-1}$, i.e. close to that of Class 2 (Fig. 9).

For a better characterization of these classes we plotted their spatial distributions in the four EBUS (Fig. 10). The spatial distribution of each class results from the dominant distributions of observations it contains. Class 1 is mainly made of observations from the southern and central Canary Current System and from the central Benguela Current system. This very productive class contains also observations 


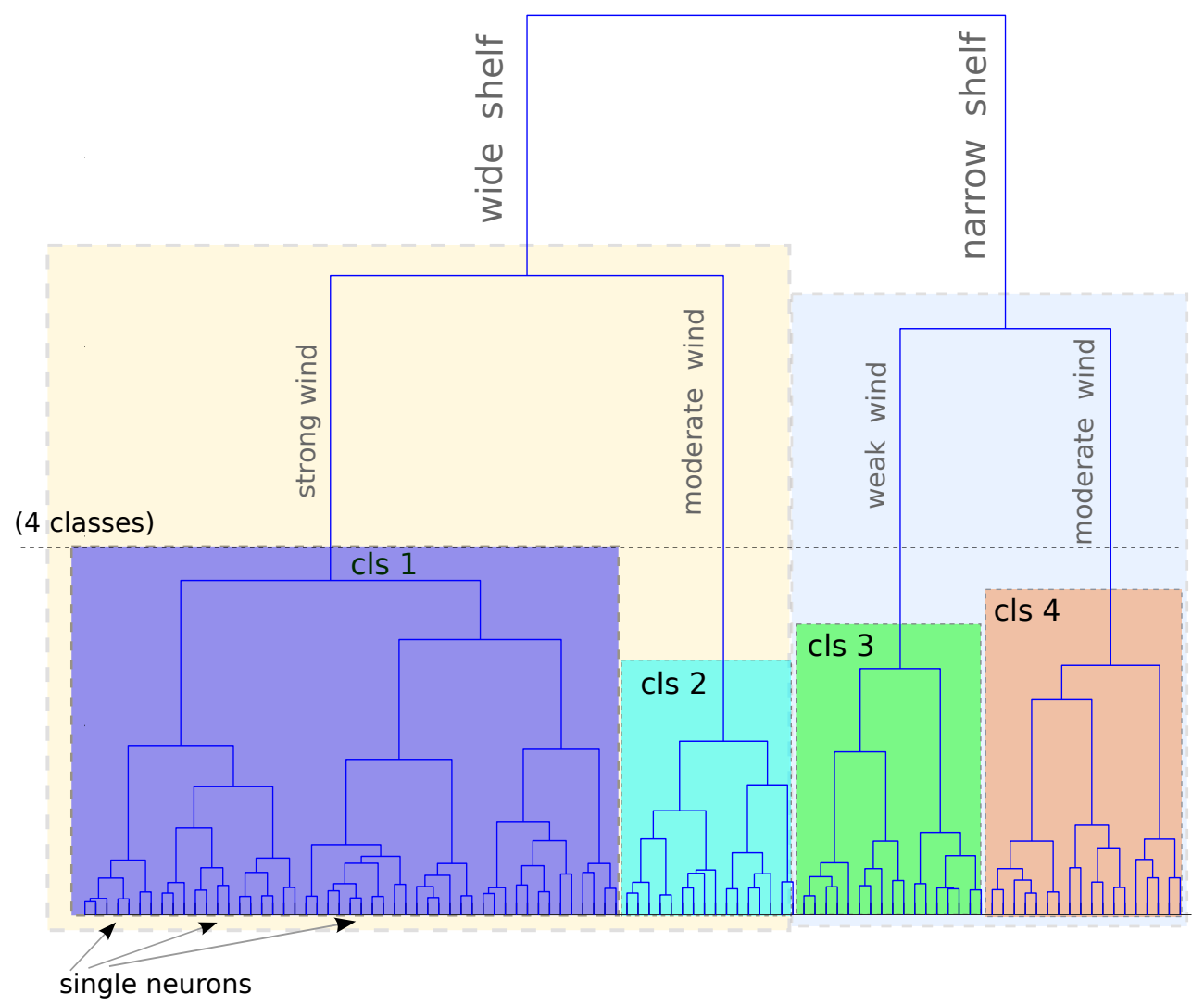

Fig. 7. HAC dendrogram showing the hierarchy of the clusters. The dendrogram was cut where the gap between two successive mergers is the largest resulting in 4 classes. They correspond to the following combinations of shelf width and wind strength: strong wind-wide shelf (class 1), moderate wind-wide shelf (class 2), weak wind-narrow shelf (class 3), and moderate wind-narrow shelf (class 4).

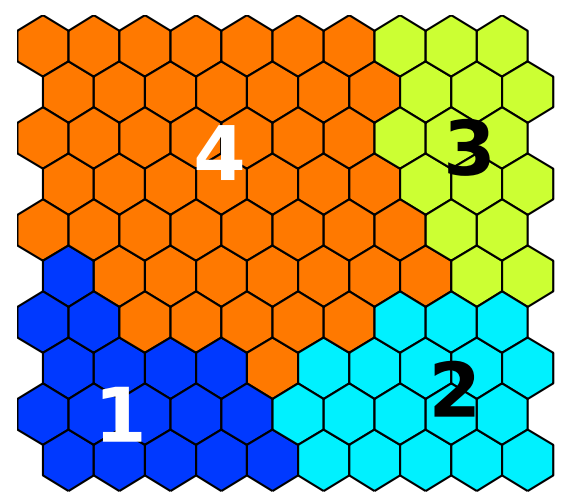

Fig. 8. The distribution of the 4 classes presented in Fig. 7 on SOM.

from the northernmost part of the Humboldt Current System. Class 2, distinguished by a wide shelf and relatively high eddy kinetic energy, corresponds to upwelling conditions observed in the southern California Current System, southern Benguela Current System and in various places of the Canary system. Class 3 that has the deepest mixed layer and the weakest wind forcing contains primarily winter observations in the northern California and Canary current systems, and in the central and southern Humboldt current system. Finally, class 4 characterized by a narrow shelf and moderate to high eddy activity, dominates in most of the California and Humboldt current systems, as well as in the northernmost part of the Benguela current system.

\subsection{Comparison of the four EBUS}

Our previous analysis reveals substantial variations of production regimes within each of the four EBUS. That is, no EBUS is made of one single class. The Canary and the Benguela current systems are spatially the most variable EBUS (i.e. they contain all classes), whereas the California and the Humboldt current systems are defined by only 2 to 3 classes. Our analysis also reveals that the closest EBUS to the Canary current system in terms of its production regime is the Benguela current system, while the Humboldt current system resembles more the California one. This becomes evident when inspecting a projection of the EBUS onto the SOM (Fig. 11). The Canary and the Benguela current systems on the one hand, and the California and Humboldt current systems on the other hand occupy common or very close 


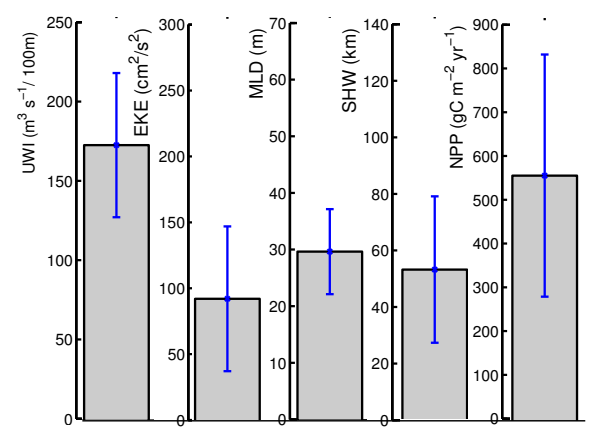

Class 1

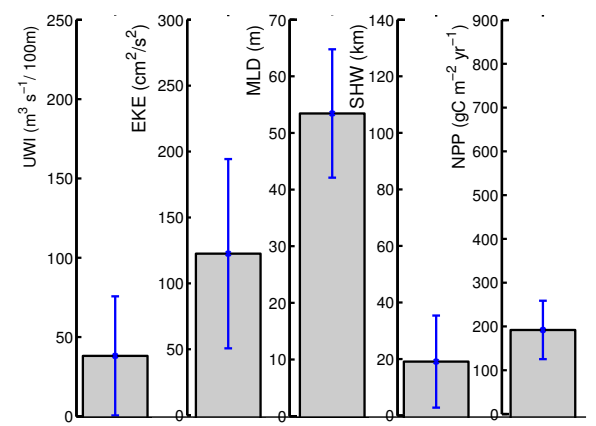

Class 3

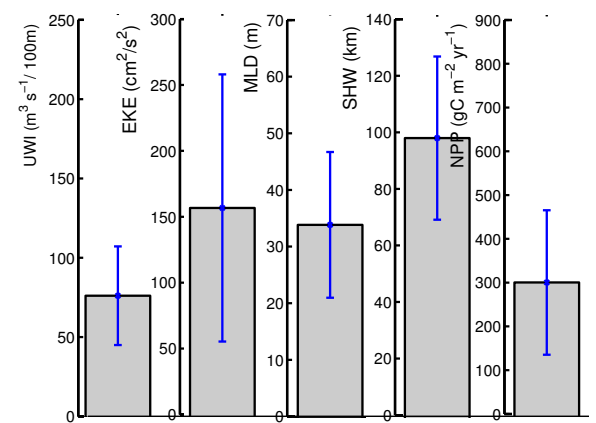

Class 2

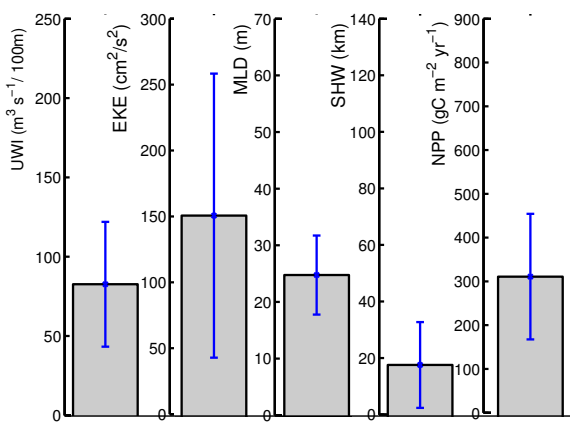

Class 4

Fig. 9. Mean (grey bars) and \pm standard deviation (blue error bars) of upwelling index, eddy kinetic energy, mixed layer depth, shelf width and net primary production associated with each of the 4 classes presented in Fig. 7.

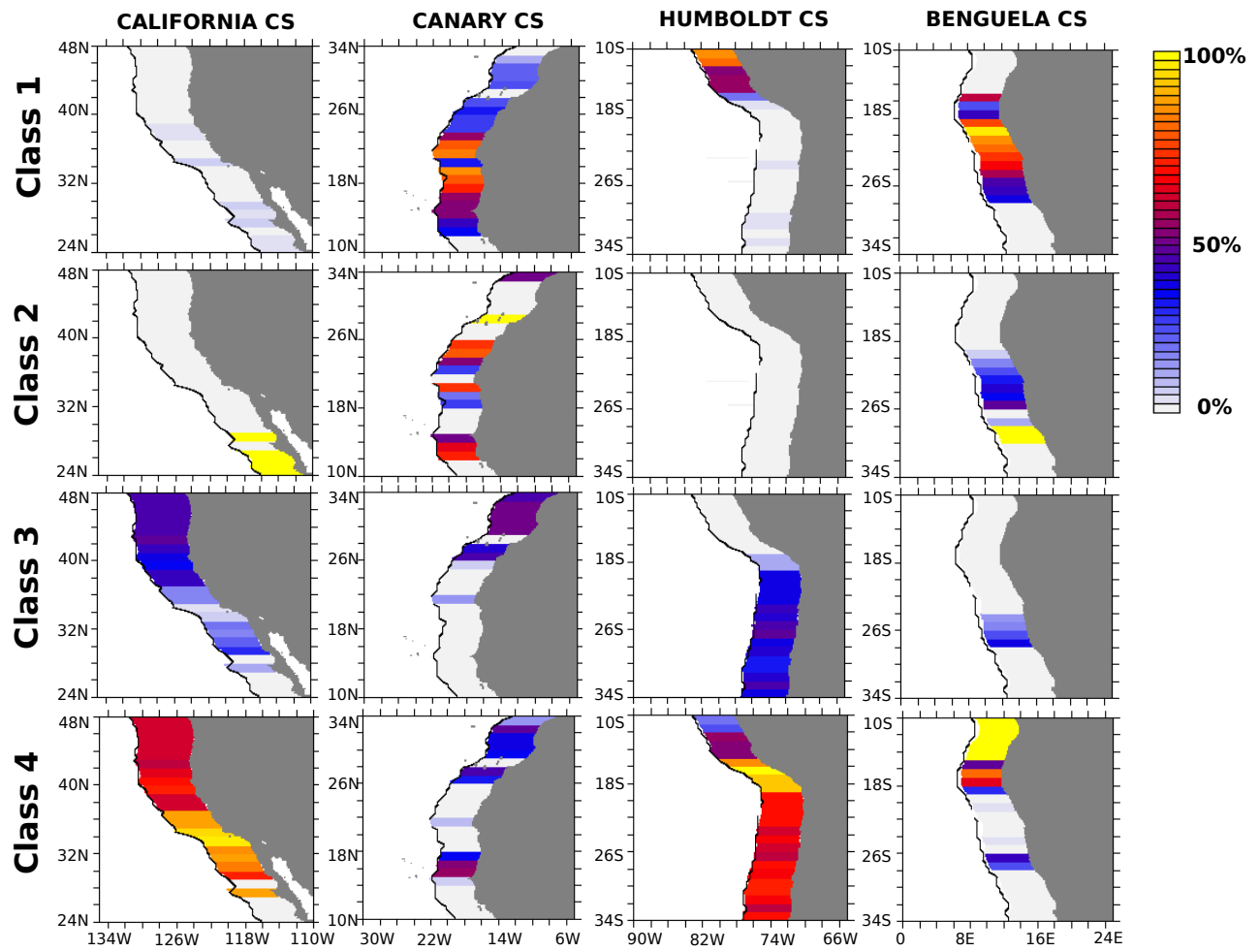

Fig. 10. Spatial distributions of the 4 classes presented in Fig. 7. For each meridional bin in the four EBUS we plotted the proportion of observations belonging to each of the 4 classes. 
CANARY CS

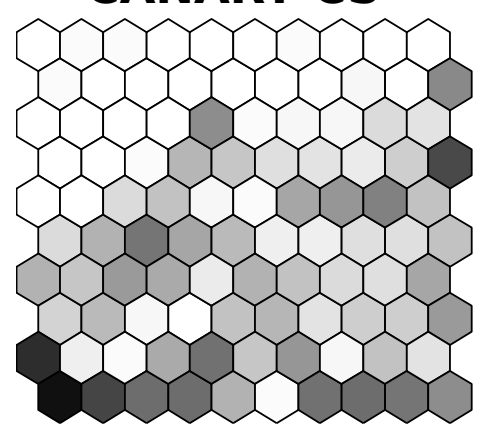

HUMBOLDT CS

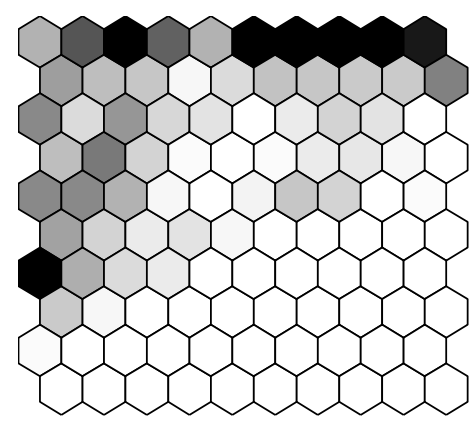

CALIFORNIA CS

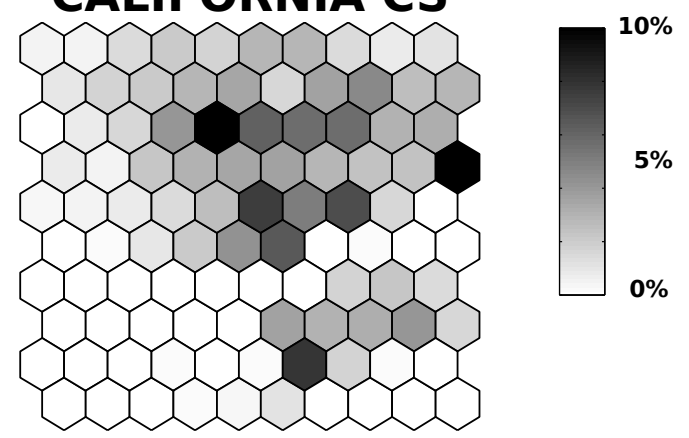

BENGUELA CS

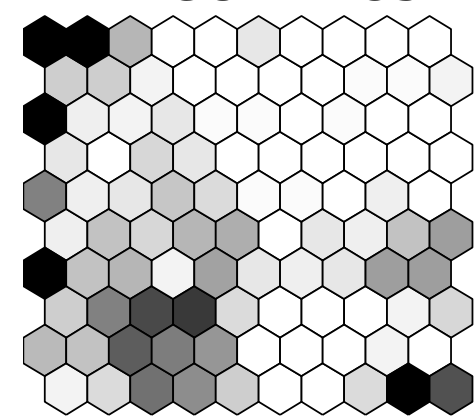

Fig. 11. Distribution of the Canary, California, Humboldt and Benguela Current systems on the SOM. The grey shading corresponds to the fraction of observations associated with each neuron.

areas on the map, which can be interpreted as a high degree of similarity.

Figure 11 also shows that the Canary and the Humboldt current systems on the one hand, and the California and the Benguela current systems on the other hand are complementary, meaning each pair fills nearly the entire map while having little in common. This implies that each of these two pairs represents nearly the whole diversity of production patterns observed in the four systems. The sketch in Fig. 12 summarizes and illustrates these findings with a graphical representation of the four EBUS, their respective production regimes and their degree of similarity.

\section{Discussion}

\subsection{The mechanisms inhibiting biological production}

A key finding of our analysis is that three factors may inhibit NPP once they become strong. These factors are (i) narrow continental shelf, (ii) deep mixed layers, and (iii) high levels of eddy activity. We next discuss the possible mechanisms that may explain our results.

Our finding suggesting that a narrow continental shelf may inhibit NPP can be interpreted by considering the effect of shelves on nutrient retention. Using idealized models, Austin and Lentz (2002) and Marchesiello and Estrade (2009) showed that wide continental shelves result in an offshore displacement of the upwelling cell, producing an area over the inner-shelf where the circulation has almost no cross-shore transport. This prevents nutrients from being advected offshore, trapping the nutrients in the innershelf region. This is consistent with the cold SST tongues observed away from the coast in the regions of the Canary system where the continental shelf is particularly wide, signaling an upwelling occurring farther offshore (Barton et al., 1977; Demarcq and Faure, 2000). This is also in agreement with recent current observations on the West Florida shelf which revealed in the case of a shallow and wide continental shelf the presence of a surface convergent flow that might favor nutrient trapping within the inner shelf (Liu and Weisberg, 2007). In addition, wide continental shelves also tend to prevent the nutrients from getting lost vertically. By trapping the exported organic nutrients at the shallow seafloor, where most of these nutrients are remineralized before getting buried, these nutrients quickly find their way back into the shallow water column, where they are soon upwelled again. When shelves are narrow, nutrients tend to get lost to the open and deep part of the ocean, resulting in lower overall nutrient levels in the waters that upwell, and hence lower NPP. Iron limitation is an additional mechanism that has been proposed to explain the role of continental shelf width (Chase et al., 2007). These authors argued that wide shelves tend to better retain river-derived iron, resulting in higher concentrations of this critical micronutrient in coastal 


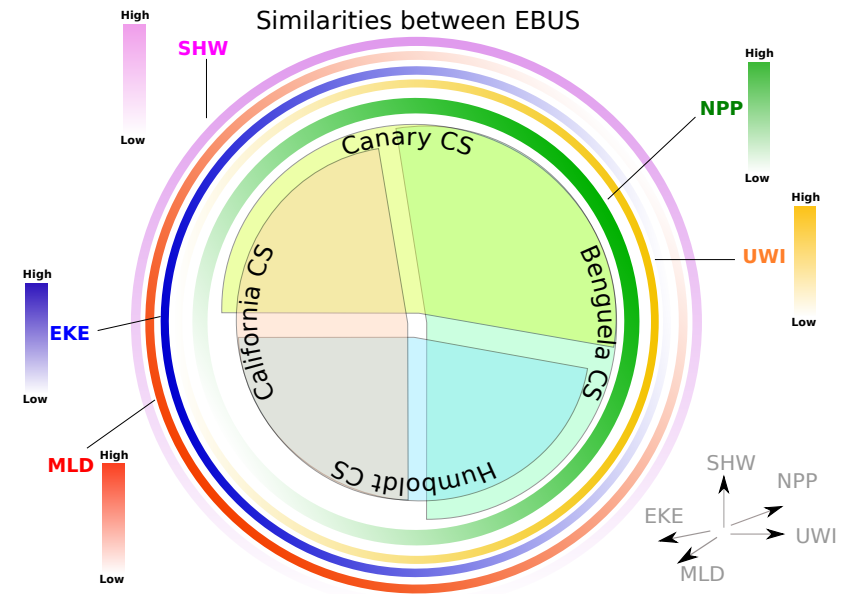

Fig. 12. A sketch illustrating the similarities and differences between the major EBUS. Pie sectors correspond to the 4 EBUS considered. For NPP and each of the 4 drivers, arrows point to areas where these variables reach maximum values (also indicated by saturated colors on the concentric circles). The area of each sector is proportional to the variability of the corresponding EBUS while overlapping sectors illustrate EBUS common features. The sketch shows that the Canary and Humboldt current systems on the one hand and the California and Benguela current systems on the other hand are complementary, meaning each pair represents most of the variability of the 4 EBUS while having little in common. Conversely, the Canary and Benguela current systems on one hand and the California and Humboldt current systems on the other hand are the most similar systems. The Canary and Benguela current systems have in common very productive coastal upwelling conditions driven by strong alongshore wind and enabled by a relatively wide continental shelf, low eddy activity and shallow mixed layer. In contrast, the California and Humboldt current systems share in common the least productive conditions with relatively weak alongshore wind, narrow shelf, moderate eddy activity and deep mixed layer. Finally, the region of overlap between the Canary and California current systems indicates similar conditions in the two systems characterized by relatively wide shelf and moderate to high eddy activity. Similarly, the overlapping area between the Benguela and Humboldt current systems illustrates common observations between these two systems characterized by narrow shelf and moderate alongshore wind.

systems with wide shelves and high freshwater input. However, since runoff freshwater inputs are generally very low in the four EBUS considered in this study (Mackas et al., 2006), this latter mechanism is likely to play a minor role in the differences of biological production discussed here.

The potential role of deep mixed layers in inhibiting NPP is likely a result of mixed layer depths regulating the average amount of light that a phytoplankton in the mixed layer is exposed to (Sverdrup, 1953). This is important in EBUS, since the physical circulation maintains quasi nutrient-replete conditions throughout most of the upwelling season, such that the light resource becomes a key limiting factor for phytoplankton growth during this period, particularly in the

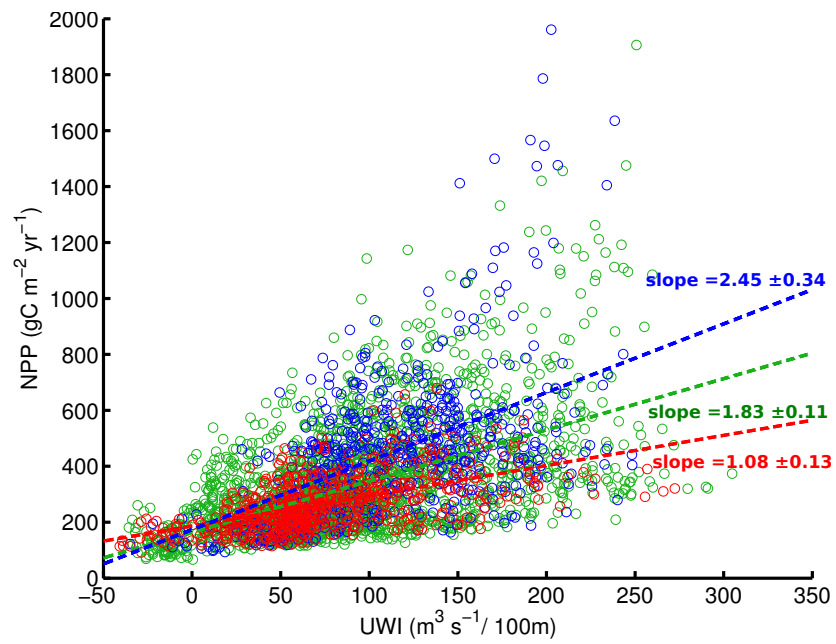

Fig. 13. The relationship between NPP and upwelling index (UWI) for strongly inhibited conditions (red circles), weakly inhibited conditions (blue circles), and intermediate conditions (green circles). The dashed lines show the corresponding linear regression lines.

nearshore area (Gruber et al., 2006). Under such conditions, deep mixed layers will tend to inhibit high rates of NPP, as has been shown in previous studies (e.g. Platt et al., 1991; Obata et al., 1996).

The inhibiting impact of meso- and submesoscale processes on NPP is less straightforward to explain, particularly since it contradicts recent findings for the open ocean, where such processes were found to enhance NPP (Falkowski et al., 1991; McGillicuddy et al., 1998). It is in line, however, with recent modeling (Marchesiello and Estrade, 2009; Gruber et al., 2011) and observational (Rossi et al., 2008) studies that focused on the eddy-induced mixing and lateral dispersion in coastal upwelling systems. Using regression analyses of satellite data in combination with numerical model simulations, Gruber et al. (2011) confirmed the reducing effect of mesoscale processes on NPP and interpreted this as the result of a nutrient leakage mechanism, by which upwelled nutrients are more efficiently removed from the nearshore regions by eddy-induced subduction and offshore transport. Additionally, Lachkar and Gruber (2011a) found that the mesoscale activity reduces the water residence times in the nearshore area, which tends to lower the efficiency by which nutrients are used in the euphotic layer. The contrasting eddy activity between the different EBUS has no single explanation. Differences in vertical stratification, wind forcing and bottom topography probably all contribute to the observed variability of the eddy activity (Hallberg and Gnanadesikan, 2006; Meredith and Hogg, 2006; Hogg et al., 2008; Marchesiello and Estrade, 2009). 


\subsection{Impact of inhibiting factors}

Our results suggest that the strength of the inhibiting factors could modulate the sensitivity of NPP to changes in wind forcing. In order to test this hypothesis, we split the data according to the strength of the inhibiting factors into three categories: (i) weakly inhibited conditions with low eddy kinetic energy $(<$ mean $-0.5 \cdot \sigma)$ and wide continental shelf $(>$ mean $+0.5 \cdot \sigma)$, (ii) strongly inhibited conditions with high eddy kinetic energy $(>$ mean $+0.5 \cdot \sigma)$ and narrow shelf $(<$ mean $-0.5 \cdot \sigma)$, and (iii) intermediate conditions for the rest of the observations. We did not include the depth of the mixed layer in our criterion for the separation of weakly and strongly inhibited conditions because observations with large MLD show very limited variability in upwelling strength and NPP, which prevents detecting statistically significant differences in their relationship. Figure 13 reveals that observations with strong inhibiting factors indeed show the lowest sensitivity of NPP to wind forcing. The slopes of a linear regression of NPP on the upwelling index vary from 1.08 $( \pm 0.13)$ for the strongly limited subset to $2.45( \pm 0.34)$ for the weakly limited subset. The differences in the slopes between the three subsets are statistically significant at the $95 \%$ level. What does this imply with regard to the sensitivity of NPP to changes in upwelling, such as predicted to occur in response to climate change (e.g. Bakun, 1990)? The majority of conditions with strong inhibiting factors are found in the California and Humboldt upwelling systems. Therefore, one may expect a weaker sensitivity of the production to wind forcing changes in the Pacific EBUS. Figure 14 suggests that NPP in the Atlantic EBUS is, indeed, more sensitive to wind forcing. This implies that under comparable alongshore wind intensification there may be a larger NPP response in the Atlantic EBUS than in the Pacific EBUS. Of course, this tentative prediction would fail if the inhibiting factors, namely the eddy activity and the mixed layer depth, undergo a substantial increase in response to intensified winds as well. Results from a recent comparative modeling study of the California and Canary upwelling systems are, however, consistent with our first prediction as they reveal that similar upwelling intensification lead indeed to larger NPP increase in the Canary current system relative to the California current system (Lachkar and Gruber, 2011b). However, this hypothesis still needs to be further confirmed by extending the investigation to the Benguela and Humboldt upwelling systems.

\section{Summary and conclusions}

We investigated the major environmental factors controlling biological production using a SOM based approach. Our aim has been to identify the leading drivers and modulating factors for NPP and to provide an objective classification and comparison of EBUS based on their production regimes.

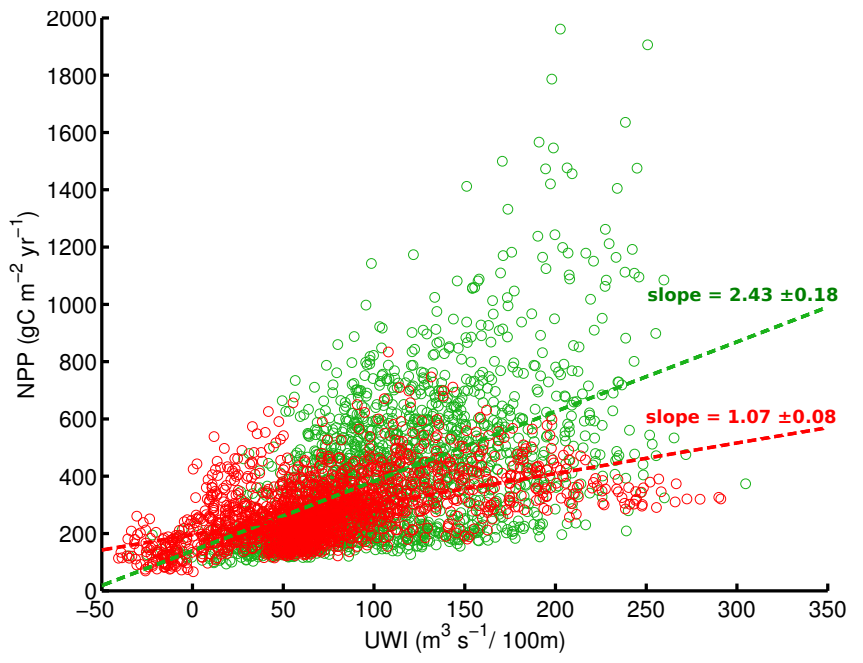

Fig. 14. The relationship between NPP and upwelling index (UWI) for the Pacific (red circles) and the Atlantic (green circles) EBUS observations. The dashed lines show the corresponding linear regression lines.

Because of their high mutual correlations, many potential drivers and factors were eliminated by SOM's feature selection algorithm, halving the initial number of drivers from 8 to 4 . Those retained are (i) alongshore wind, expressed in terms of an upwelling index, (ii) eddy kinetic energy, (iii) continental shelf width and (iv) mixed layer depth. SOM aggregated these 4 drivers and NPP into 100 patterns of physical and environmental conditions favoring or inhibiting NPP. While confirming the dominant role of upwelling-favorable alongshore wind in controlling the level of NPP in EBUS, our analysis revealed that the three remaining factors may strongly inhibit the biological production when reaching extreme values.

Grouping the 100 patterns of the SOM with a HAC clustering method led to a typology of EBUS made of 4 distinct classes of production regimes. These are composed of one highly productive class dominating the central Benguela and the central and southern part of the Canary current system, in addition to three less productive classes dominating most of the California and Humboldt current systems as well as the northern part of the Canary system and northern and southern Benguela current system. Despite substantial variability in patterns within each of the four EBUS, a similarity analysis revealed that the Atlantic EBUS on the one hand and the Pacific EBUS on the other hand show fundamental contrasts. The distinction relies on the strength of the inhibiting factors, namely the shelf width and eddy kinetic energy, which are generally much stronger in the Pacific EBUS than in the Atlantic EBUS. Therefore, our results suggest that climate change driven increase in the upwelling favorable winds may lead to a stronger biological response in the Atlantic compared to the Pacific EBUS, with major implications for the 
biogeochemical cycles and fisheries in these marine ecosystems. This clearly merits further in-depth investigation involving global and regional models.

\section{Supplement related to this article is available online at: http://www.biogeosciences.net/9/293/2012/ bg-9-293-2012-supplement.pdf.}

Acknowledgements. We are grateful to N. Lovenduski for preparing the satellite-based production dataset used in this study. Support for this research has come from the Swiss Federal Institute of Technology Zurich (ETH Zurich). We thank the various providers of the satellite data, in particular the SeaWiFS Project (Code 970.2) sponsored by NASA's Mission to Planet Earth program, as well as Ssalto/Duacs and Aviso teams for the production and the distribution of altimeter products, respectively. We thank Y. Liu and a second reviewer for their constructive comments that helped to improve the paper.

Edited by: C. Robinson

\section{References}

Allen, J.: Upwelling and Coastal Jets in a Continuously Stratified Ocean, J. Phys. Oceanogr., 3, 245-257, 1973.

Arístegui, J., Barton, E. D., Tett, P., Montero, M. F., GarcíaMuñoz, M., Basterretxea, G., Cussatlegras, A., Ojeda, A., and de Armas, D.: Variability in plankton community structure, metabolism, and vertical carbon fluxes along an upwelling filament (Cape Juby, NW Africa), Prog. Oceanogr., 62, 95-113, doi:10.1016/j.pocean.2004.07.004, 2004.

Astel, A., Tsakovski, S., Barbieri, P., and Simeonov, V.: Comparison of self-organizing maps classification approach with cluster and principal components analysis for large environmental data sets, Water Research, 41, 4566-4578, doi:10.1016/j.watres.2007.06.030, 2007.

Austin, J. A. and Lentz, S. J.: The Inner Shelf Response to WindDriven Upwelling and Downwelling, J. Phys. Oceanogr., 32, 2171-2193, 2002.

Bakun, A.: Global Climate Change and Intensification of Coastal Ocean Upwelling, Science, 247, 198-201, doi:10.1126/science.247.4939.198, 1990.

Bakun, A.: Patterns in the ocean: Ocean processes and marine population dynamics, California Sea Grant College System, National Oceanic and Atmospheric Adminstration in cooperation with Centro de Investigaciones Biologicas del Noroeste, La Paz, BCS Mexico, 323 pp., ISBN:1-888691-01-8, 1996.

Barton, E. D., Huyer, A. H., and Smith, R. L.: Temporal variation observed in the hydrographic regime near Cabo Corveiro in the Northwest African upwelling region, February to April 1974. Deep Sea Res., 24, 7-23, 1977.

Barton, E. D., Arístegui, J., Tett, P., Cantón, M., García-Braun, J., Hernández-Len, S., Nykjaer, L., Almeida, C., Almunia, J., Ballesteros, S., Basterretxea, G., Escánez, J., García-Weill, L., Hernández-Guerra, A., López-Laatzen, F., Molina, R., Montero, M. F., Navarro-Pérez, E., Rodrguez, J. M., van Lenning, K., Vlez, H., and Wild, K.: The transition zone of the Ca- nary Current upwelling region, Prog. Oceanogr., 41, 455-504, doi:10.1016/S0079-6611(98)00023-8, 1998.

Batteen, M. L., Martinho, A. S., Miller, H. A., and McClean, J. L.: A process-oriented modelling study of the coastal Canary and Iberian Current system, Ocean Modell., 18, 1-36, doi:10.1016/j.ocemod.2007.02.006, 2007.

Behrenfeld, M. J. and Falkowski, P. G.: Photosynthetic Rates Derived from Satellite-Based Chlorophyll Concentration, Limnol. Oceanogr., 42, 1-20, 1997.

Belsley, D. A., Kuh, E., and Welsch, R. E.: Regression Diagnostics: Identifying Influential Data and Sources of Collinearity, WileyInterscience, New York, USA, 292 pp., ISBN:9780471691174, 1980.

Benabdeslem, K. and Lebbah, M.: Feature Selection for SelfOrganizing Map, in: Information Technology Interface-ITI 2007, 29th International Conference on Information Technology Interfaces, 45-50, doi:10.1109/ITI.2007.4283742, 2007.

Brink, K.: The near-surface dynamics of coastal upwelling, Prog. Ocean., 12, 223-257, doi:10.1016/0079-6611(83)90009-5, 1983a.

Brink, K.: The physical environment of the Peruvian upwelling system, Prog. Oceanogr., 12, 285-305, doi:10.1016/00796611(83)90011-3, 1983b.

Brink, K. H.: Coastal Physical Processes Overview, Harvard University Press, edited by: Robinson, A. R. and Brink, K. H. edn., 13, 37-60, 2005.

Carr, M.: Estimation of potential productivity in Eastern Boundary Currents using remote sensing, Deep Sea Res., 49, 59-80, doi:10.1016/S0967-0645(01)00094-7, 2001.

Carr, M. and Kearns, E. J.: Production regimes in four Eastern Boundary Current systems, Deep Sea Res. II: Topical Studies Oceanography, 50, 3199-3221, doi:10.1016/j.dsr2.2003.07.015, 2003.

Cavazos, T.: Using Self-Organizing Maps to Investigate Extreme Climate Events: An Application to Wintertime Precipitation in the Balkans, J. Clim., 13, 1718-1732, 2000.

Chase, Z., Strutton, P. G., and Hales, B.: Iron links river runoff and shelf width to phytoplankton biomass along the US West Coast, Geophys. Res. Lett., 34, 4 pp., L04607, doi:10.1029/2006GL028069, 2007.

Chavez, F. P. and Takahashi, T.: Coastal oceans, A report by the US climate change science program and the subcommittee on global change research, National Ocean and Atmospheric Administration, Climate Program Office, Silver Spring, MD, USA, King, A. W., Dilling, L., Zimmerman, G. P., Fairman,D. M., houghton, R. A., Marland, G. H., Rose,A. Z., and Wilbanks, T. J., 83-92, 2007.

Chen, D. and Ware, D.: A neural network model for forecasting fish stock recruitment, Canadian J. Fish. Aquat. Sci., 56, 2385-2396, doi:10.1139/cjfas-56-12-2385, 1999.

Cohen, P., Cohen, J., West, S. G., and Aiken, L. S.: Applied Multiple Regression/Correlation Analysis for the Behavioral Sciences, Lawrence Erlbaum, third edn., 2002.

Conkright, M. E., Locarnini, R. A., Garcia, H. E., O’Brien, T. D., Boyer, T. P., Stephen, C., and Antonov, J. I.: World Ocean Atlas 2001: Objective Analyses, Data Statistics, and Figures, CDROM Documentation, Tech. rep., National Oceanographic Data Center, Silver Spring, MD, USA, 17 pp., 2002.

Dayhoff, J. E.: Neural network architectures: an introduction, Van 
Nostrand Reinhold Co., New York, USA, 259 pp., 1990.

de Boyer Montégut, C., Madec, G., Fischer, A. S., Lazar, A., and Iudicone, D.: Mixed layer depth over the global ocean: An examination of profile data and a profile-based climatology, J. Geophys. Res., 109, C12003, doi:10.1029/2004JC002378, 2004.

Demarcq, H, and Faure, V.:Coastal upwelling and associated retention indices derived from satellite SST. Application to octopus vulgaris recruitment, Ocean. Acta 23, 391-408, 2000.

Falkowski, P. G., Ziemann, D., Kolber, Z., and Bienfang, P. K.: Role of eddy pumping in enhancing primary production in the ocean, Nature, 352, 55-58, doi:10.1038/352055a0, 1991.

FAO: The State of World Fisheries and Aquaculture 2008, Food \& Agriculture Org, Pap/Cdr edn., 2009.

Fennel, W.: Theory of the Benguela Upwelling System, J. Phys. Oceanogr., 29, 177-190, 1999.

Gotelli, N. J. and Ellison, A. M.: A Primer Of Ecological Statistics, Sinauer Associates, 1 edn., 2004.

Gruber, N., Frenzel, H., Doney, S. C., Marchesiello, P., McWilliams, J. C., Moisan, J. R., Oram, J. J., Plattner, G., and Stolzenbach, K. D.: Eddy-resolving simulation of plankton ecosystem dynamics in the California Current System, Deep Sea Res., 53, 1483-1516, 2006.

Gruber, N., Lachkar, Z., Frenzel, H., Marchesiello, P., Munnich, M., McWilliams, J. C., Nagai, T., and Plattner, G.: Mesoscale eddy-induced reduction of biological production in eastern boundary upwelling systems, Nature Geosci., 4, 787-792, doi:10.1038/ngeo1273, 2011.

Hallberg, R. and Gnanadesikan, A.: The Role of Eddies in Determining the Structure and Response of the Wind-Driven Southern Hemisphere Overturning: Results from the Modeling Eddies in the Southern Ocean (MESO) Project, J. Phys. Oceanogr., 36, 2232-2252, 2006.

Harrell, F. E. J.: Regression Modeling Strategies, Springer, corrected edn., 2001.

Hickey, B.: Coastal oceanography of western North America from the tip of Baja California to Vancouver Island, New York, USA, J. Wiley and Sons edn., 11, 345-394, 1998.

Hill, E. A., Hickey, B., Shillington, F. A., Strub, T. P., Brink, K. H., Barton, E. D., and Thomas, A.: Eastern boundary Currents: A Pan-Regional Review, John Wiley and Sons Inc., Robinson, A. R. and Brink, K. H., edn., 11 of The Sea 29-67, 1998.

Hogg, A. M., Meredith, M. P., Blundell, J. R., and Wilson, C.: Eddy Heat Flux in the Southern Ocean: Response to Variable Wind Forcing, J. Climate, 21, 608-620, 2008.

Jain, A. K. and Dubes, R. C.: Algorithms for Clustering Data, Prentice Hall College Div, 304 pp., ISBN:013022278X, 1988.

Kahru, M., Kudela, R., Manzano-Sarabia, M., and Mitchell, B. G.: Trends in primary production in the California Current detected with satellite data, J. Geophys. Res., 114, C02004, doi:10.1029/2008JC004979, 2009.

Kohonen, T.: Self-organization and associative memory, SpringerVerlag New York, Inc. New York, NY, USA, 312 pp., 1989.

Kohonen, T.: Self-Organizing Maps, Springer, 3rd edn., 2000.

Lachkar, Z., and Gruber, N.: What controls biological productivity in coastal upwelling systems? Insights from a comparative modeling study, Biogeosciences, 8, 9901-9941, doi:10.5194/bgd-89901-2011, 2011.

Lachkar, Z., and Gruber, N.: Response of biological productivity and air-sea $\mathrm{CO}_{2}$ fluxes to upwelling intensification in the Califor- nia and Canary Current Systems, J. Marine Syst., under review, 2011.

Laha, A.: Detecting Topology Preserving Feature Subset with SOM, 40-48, 2005.

Laine, S. and Similä, T.: Using SOM-Based Data Binning to Support Supervised Variable Selection, 172-180, 2004.

Leloup, J., Lachkar, Z., Boulanger, J., and Thiria, S.: Detecting decadal changes in ENSO using neural networks, Clim. Dynam., 28, 147-162, doi:10.1007/s00382-006-0173-1, 2007.

Liu, H. and Motoda, H.: Feature Selection for Knowledge Discovery and Data Mining, Springer, 1st edn., 1998.

Liu, Y. and Weisberg, R.: Patterns of ocean current variability on the West Florida Shelf using the self-organizing map, J. Geophys. Res, 110, C06003, doi:10.1029/2004JC002786, 2005.

Liu, Y. and Weisberg, R.: Ocean currents and sea surface heights estimated across the West Florida Shelf, J. Phys. Oceanogr., 37, 1697-1713, 2007.

Liu, Y., Weisberg, R., and Mooers, C. N. K.: Performance evaluation of the self-organizing map for feature extraction, J. Geophys. Res., 111, C05018, doi:10.1029/2005JC003117, 2006.

Longhurst, A., Sathyendranath, S., Platt, T., and Caverhill, C.: An estimate of global primary production in the ocean from satellite radiometer data, J. Plankton Res., 17, 1245-1271, doi:10.1093/plankt/17.6.1245, 1995.

Mackas, D. L., Strub, P. T., Thomas, A., and Montecino, V.: Eastern ocean boundaries, Harvard University Press, edited by: Robinson, A. R. and Brink, K. H., 2 of The Sea, 21-59, 2006.

Marchesiello, P. and Estrade, P.: Eddy activity and mixing in upwelling systems: a comparative study of Northwest Africa and California regions, Int. J. Earth Sci., 98, 299-308, doi:10.1007/s00531-007-0235-6, 2009.

Marra, J., Ho, C., and Trees, C.: An alternative algorithm for the calculation of primary productivity from remote sensing data, Technical LDEO-2003-1, 2003.

Matsumoto, K., Takanezawa, T., and Ooe, M.: Ocean tide models developed by assimilating TOPEX/POSEIDON altimeter data into hydrodynamical model: A global model and a regional model around Japan, J. Oceanogr., 56, 567-581, 2000.

McCreary, J. P., Kundu, P. K., and Chao, S.: On the dynamics of the California Current system, J. Mar. Res., 45, 1-32, doi:10.1357/002224087788400945, 1987.

McGillicuddy, D. J., Robinson, A. R., Siegel, D. A., Jannasch, H. W., Johnson, R., Dickey, T. D., McNeil, J., Michaels, A. F., and Knap, A. H.: Influence of mesoscale eddies on new production in the Sargasso Sea, Nature, 394, 263-266, doi:10.1038/28367, 1998.

McGregor, H. V., Dima, M., Fischer, H. W., and Mulitza, S.: Rapid 20th-Century Increase in Coastal Upwelling off Northwest Africa, Science, 315, 637-639, doi:10.1126/science.1134839, 2007.

Mendelssohn, R.: common and uncommon trends in SST and wind stress in the California and Peru-Chile current systems, Prog. Oceanogr., 53, 141-162, doi:10.1016/S0079-6611(02)00028-9, 2002.

Meredith, M. P. and Hogg, A. M.: Circumpolar response of Southern Ocean eddy activity to a change in the Southern Annular Mode, Geophys. Res. Lett., 33, L16608, doi:10.1029/2006GL026499, 2006.

Mittelstaedt, E.: The upwelling area off Northwest Africa - A 
description of phenomena related to coastal upwelling, Prog. Oceanogr., 12, 307-331, doi:10.1016/0079-6611(83)90012-5, 1983.

Muller-Karger, F. E., Varela, R., Thunell, R., Luerssen, R., Hu, C., and Walsh, J. J.: The importance of continental margins in the global carbon cycle, Geophys. Res. Lett., 32, L01602, doi:10.1029/2004GL021346, 2005.

Obata, A., Ishizaka, J., and Endoh, M.: Global verification of critical depth theory for phytoplankton bloom with climatological in situ temperature and satellite ocean color data, J. Geophys. Res., 101, 20657-20667, 1996.

Park, Y., Kwak, I., Chon, T., Kim, J., and Jörgensen, S. E.: Implementation of artificial neural networks in patterning and prediction of exergy in response to temporal dynamics of benthic macroinvertebrate communities in streams, Ecol. Model., 146, 143-157, doi:10.1016/S0304-3800(01)00302-7, 2001.

Park, Y., Crghino, R., Compin, A., and Lek, S.: Applications of artificial neural networks for patterning and predicting aquatic insect species richness in running waters, Ecol. Model., 160, 265-280, doi:10.1016/S0304-3800(02)00258-2, 2003.

Patti, B., Guisande, C., Vergara, A. R., Riveiro, I., Maneiro, I., Barreiro, A., Bonanno, A., Buscaino, G., Cuttitta, A., and Basilone, G.: Factors responsible for the differences in satellitebased chlorophyll - a concentration between the major global upwelling areas, Estuarine, Coast. Shelf Sci., 76, 4, 775-786, 2008.

Pauly, D. and Christensen, V.: Primary production required to sustain global fisheries, Nature, 374, 255-257, doi:10.1038/374255a0, 1995 .

Platt, T., Bird, D. F., and Sathyendranath, S.: Critical Depth and Marine Primary Production, Proc. Roy. Soc. Lnd., 246, 205-217, doi:10.1098/rspb.1991.0146, 1991.

Reusch, D. B., Alley, R. B., and Hewitson, B. C.: North Atlantic climate variability from a self-organizing map perspective, J. Geophys. Res., 112, D02104, doi:10.1029/2006JD007460, 2007.

Richardson, A. J., Pfaff, M. C., Field, J. G., Silulwane, N. F., and Shillington, F. A.: Identifying characteristic chlorophyll a profiles in the coastal domain using an artificial neural network, J. Plankton Res., 24, 1289-1303, doi:10.1093/plankt/24.12.1289, 2002.

Richardson, A. J., Risien, C., and Shillington, F. A.: Using selforganizing maps to identify patterns in satellite imagery, Prog. Oceanogr., 59, 223-239, doi:10.1016/j.pocean.2003.07.006, 2003.
Ritter, H. and Schulten, K.: Kohonen's self-organizing maps: exploring their computational capabilities, in: Neural Networks, 1988., IEEE International Conference on IEEE international conference on Neural Networks, 109-116, doi:10.1109/ICNN.1988.23838, 1988.

Rossi, V., López, C., Sudre, J., Hernández-García, E., and Garçon, V.: Comparative study of mixing and biological activity of the Benguela and Canary upwelling systems, Geophys. Res. Lett., 35, L11602, doi:10.1029/2008GL033610, 2008.

Rossi, V., López, C., Hernández-García, E., Sudre, J., Garon, V., and Morel, Y.: Surface mixing and biological activity in the four Eastern Boundary Upwelling Systems, Nonlin. Processes Geophys., 16, 557-568, doi:10.5194/npg-16-557-2009, 2009.

Saraceno, M., Provost, C., and Lebbah, M.: Biophysical regions identification using an artificial neuronal network: A case study in the South Western Atlantic, Adv. Space Res., 37, 793-805, doi:10.1016/j.asr.2005.11.005, 2006

Schwing, F. B. and Mendelssohn, R.: Increased coastal upwelling in the California Current System, J. Geophys. Res., 102, 34213438, doi:10.1029/96JC03591, 1997.

Shannon, L., Crawford, R., Pollock, D., Hutchings, L., Boyd, A., Taunton-Clark, J., Badenhorst, A., Melville-Smith, R., Augustyn, C., Cochrane, K., Hampton, I., Nelson, G., Japp, D., and Tarr, R.: The 1980s a decade of change in the Benguela ecosystem, South Afr. J. Marine Sci., 12, 271-296, 1992.

Smith, W. H. and Sandwell, D. T.: Global Sea Floor Topography from Satellite Altimetry and Ship Depth Soundings, Science, 277, 1956-1962, doi:10.1126/science.277.5334.1956, 1997.

Solidoro, C., Bandelj, V., Barbieri, P., Cossarini, G., and Umani, S. F.: Understanding dynamic of biogeochemical properties in the northern Adriatic Sea by using self-organizing maps and K-means clustering, J. Geophys. Res, 112, C07S90, doi:10.1029/2006JC003553,2007.

Sverdrup, H. U.: On conditions for the vernal blooming of phytoplankton, Journal du Conseil - Conseil Permanent International Pour L'exploration de la Mer, 287-295, 1953.

Volkov, D. L., Larnicol, G., and Dorandeu, J.: Improving the quality of satellite altimetry data over continental shelves, J. Geophys. Res., 112, C06020, doi:10.1029/2006JC003765, 2007. 